\title{
BLICKDIAGNOSE
}

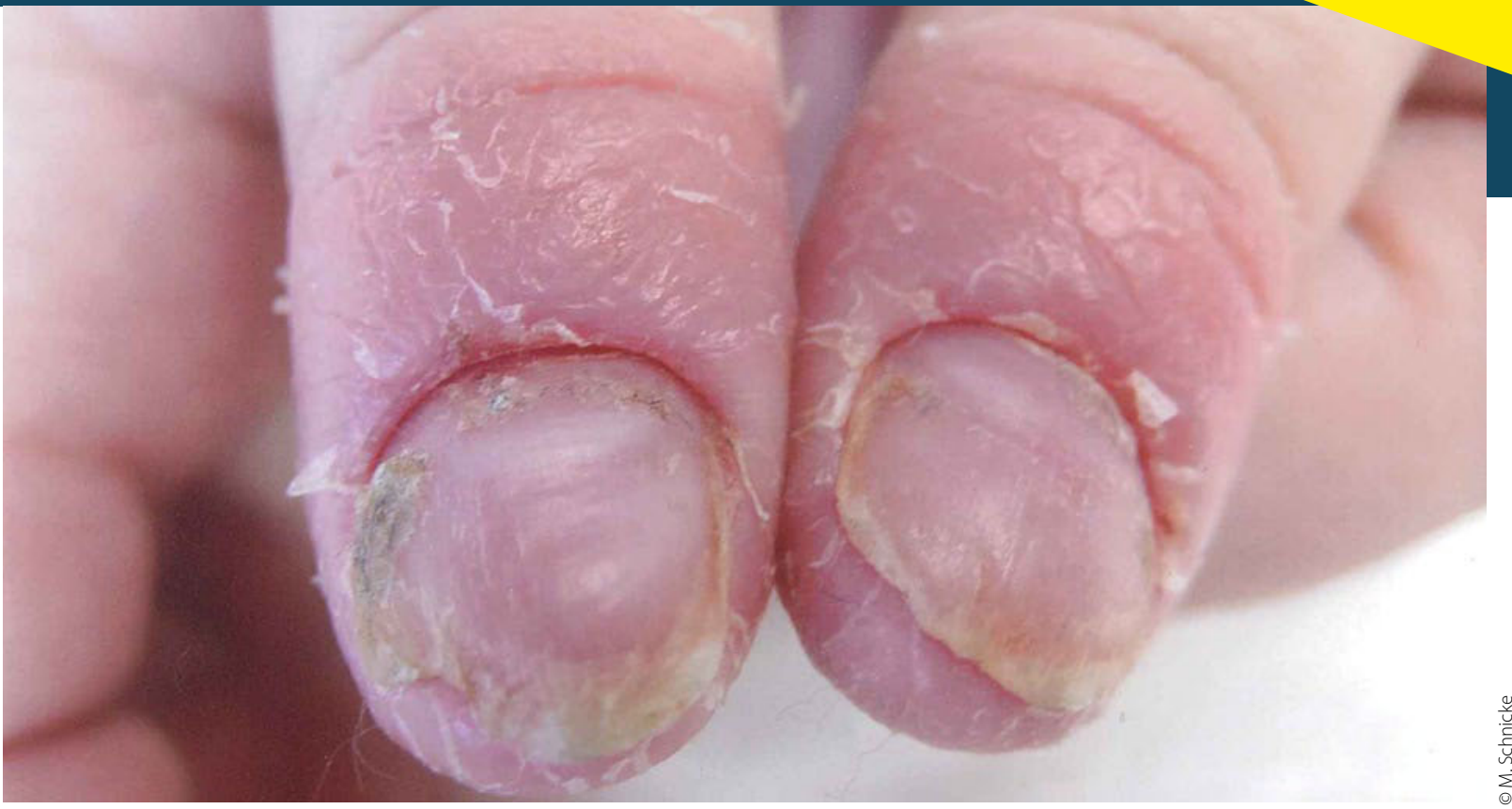

Atopischer Daumen

\section{Pilz? Nein, Gameboy!}

Immer wieder erscheinen - meist junge Patienten mit Daumen- und Fingerkuppenekzemen, wobei leider gerne in der Primärbehandlung unter der Annahme, es handele sich um eine Pilzerkrankung, mit Antimykotika behandelt wird. Diese verschlimmern das Krankheitsbild dann noch. Ähnliches gilt übrigens für den atopischen Winterfuß im Rahmen der Neurodermitis.

— Bei dem achtjährigen Patienten, der in der Freizeit gerne Basketball spielt, der aber auch täglich mit dem Gameboy hantiert, war es durch mechanische Irritationen zum Ekzem der Daumenkuppen gekommen, mit Dystrophien der Nagelhäutchen und auch Nägel. In der Annahme, es handele sich um eine Pilzerkrankung, wurde wochenlang mit Lamisil-Creme behandelt, wobei diese Kinder auf die Fehlbehandlung sehr aggressiv mit einer Verschlimmerung des Ekzems reagieren. Auch hier war der Pilzabstrich selbstverständlich negativ, sodass auf Dermatop ${ }^{\circledR}$-Salbe (Prednicabat) umgestellt wurde, was innerhalb weniger Wochen zur völligen Abheilung führte. Gerade Kinderärzte und Praktiker sehen diese Anfangs- befunde in der Praxis sehr häufig und sollten Pilztherapien nur dann verordnen, wenn mittels Kultur oder Mikroskop eine Pilzerkrankung auch sicher nachgewiesen werden kann. Ansonsten ist es günstiger, die Behandlung mit einem milden Kortison zu beginnen. Bei NichtAnsprechen kann immer noch eine Pilzkultur entnommen werden, die nach Kortison um so besser angeht.

In hartnäckigen Fällen, insbesondere beim atopischen Winterfuß, nehmen die Hautärzte gerne als Grundlage eine weiche Zinkpaste, z. B. Triamcinolon acet 0,015 in Pasta Zinci Mollis ad, 15,0. Mit bestem Erfolg.

Keywords: endogenous eczema, winter eczema

- Dr. med. Michael Schnicke, Hautarzt, Bonn Center, Bundeskanzlerplatz, D-53113 Bonn

\section{Weitere Infos auf springermedizin.de}

Weitere Blickdiagnosen finden Sie im Internet unter: - http://www.springermedizin.de/blickdiagnose 